\title{
An assessment of hydrates inhibition in deepwater production systems using low-dosage hydrate inhibitor and monoethylene glycol
}

\author{
Ndubuisi U. Okereke ${ }^{2}$ (D) Pius E. Edet ${ }^{1} \cdot$ Yahaya D. Baba ${ }^{4} \cdot$ Nkemakolam C. Izuwa $^{2} \cdot$ Sunday Kanshio $^{3} \cdot \mathrm{Ngozi} \mathrm{Nwogu}^{2}$. \\ Funsho A. Afolabi ${ }^{1}$. Onyebuchi Nwanwe ${ }^{2}$
}

Received: 14 July 2019 / Accepted: 24 November 2019 / Published online: 30 November 2019

(c) The Author(s) 2019

\begin{abstract}
In this study, a deepwater pipeline-riser system that experienced hydrates was modelled in MAXIMUS 6.20 (an integrated production modelling tool) to understand, predict and mitigate hydrates formation in typical deepwater system. Highlights of the results from this study suggest that the injection of low-dosage hydrate inhibitors (LDHIs) into the hydrate-forming structures within the multiphase flow stream disperses the hydrates particles in an irregular manner and subsequently decreases the nucleation rate of the hydrate and prevents the formation of hydrates. This study found that the cost of using monoethylene glycol was significantly higher than that of LDHI by over $\$ 500 /$ day although low-dosage hydrate inhibitors have initial relatively high CAPEX. In the long run, its OPEX is relatively low, making it cost-effective for hydrate inhibition in deepwater scenarios.
\end{abstract}

Keywords Hydrates $\cdot$ Inhibition $\cdot$ Deepwater $\cdot$ Nucleation rate $\cdot$ MAXIMUS

\section{Introduction}

Pipeline-riser system plugging, resulting from hydrates formation, is a major flow assurance issue in the subsea/offshore operations of oil and gas assets. Typical expenses for the prevention of hydrate formation range between 10 and $15 \%$ of production cost (Makogon et al. 1996). There is an urgent need to maximize production rates from subsea wells, in order to meet increasing energy demand and at a moderate operational cost. These hydrates form due to the presence of free water and gas molecule in the multiphase flow stream from the reservoir and low temperature and high pressure of

Ndubuisi U. Okereke

ndubuisi.okereke@futo.edu.ng

Yahaya D. Baba

y.baba@sheffield.ac.uk

1 Department of Chemical and Petroleum Engineering, Afe Babalola University, Ado-Ekiti, Nigeria

2 Department of Petroleum Engineering, Federal University of Technology, Owerri, Nigeria

3 Department of Petroleum and Gas Engineering, Baze University, Abuja, Nigeria

4 Department of Chemical and Biological Engineering, University of Sheffield, Sheffield S1 3JD, UK the subsea environment. Failure to mitigate the occurrence of hydrates could lead to restriction of flow and subsequent low production or even complete shutdown of production. Possible rupture of the pipeline-riser section could also occur as a result of the high-pressure regime the pipelineriser system could be operating at. This study focused on the development of a numerical simulation model for a typical deepwater pipeline-riser system and comparing the effectiveness of monoethylene glycol (MEG) and low-dosage hydrate inhibitor (LDHI) as hydrates inhibition strategies.

\section{Problem statement}

The oil and gas industry currently depends mainly on monoethylene glycol (MEG) for hydrates inhibition. However, in recent times, MEG has proved a bit expensive. Also, there has been recent field experience of hydrates forming on the MEG lines. Hence, this study focused on comparing MEG with LDHI in order to evaluate the technical effectiveness and cost-effectiveness of both approaches in inhibiting hydrates formation. 


\section{Literature review}

Flow assurance refers to the ability to effectively manage the flow of multiphase flow streams/hydrocarbons from the reservoir to the topsides. It is a relatively new concept in the oil and gas industry and is currently gaining huge attention. Key flow assurance issues include: severe slugging prediction and mitigation in deepwater scenarios (Okereke and Omotara 2018; Io et al. 2017), wax formation (Minami et al. 1999) and hydrates formation and mitigation in deepwater scenarios (Wang et al. 2018).

\section{Hydrates formation}

According to Fu et al. (2001), a hydrate is a crystalline icelike solid that forms when gas molecules get trapped in hydrogen-bonded water cages under low-temperature and high-pressure conditions. It is generally recognized that two main forms of hydrates structure exist in the gas processing industry. Structure I is formed by water and smaller molecules such as methane, ethane, carbon dioxide and hydrogen sulphide, while Structure II is formed by larger molecules such as propane and isobutene (Processors et al. 1967). In both cases, the water molecules form the crystalline structure or lattice and the hydrate formers occupy the cavity of that lattice. In recent times, efforts have been directed towards the prediction of a third type of hydrate structure, Structure $\mathrm{H}$ with large molecules. Typical hydrate structures are shown in Fig. 1.

Gas hydrates are similar in appearance to ice. Both materials have crystalline structures that exhibit similar characteristics with the important difference that natural gas hydrate has a natural gas guest molecule, an integral part of its structure. Depending on the gas composition and the pressure, gas hydrates can form at temperatures up to $86^{\circ} \mathrm{F}$, where gas coexists with water (Clark et al. 2005a).

The mechanism of hydrates formation in pipes is further illustrated in Fig. 2, with water presence in the pipeline system, giving rise to the trapping of the gas molecules within the hydrates-forming cage-like structure (the hydrate shell growth stage). This is followed by the agglomeration of
Fig. 1 Gas hydrates structures (Processors et al. 1967)
Fig. 2 Hydrate plug formation in pipeline (Clark et al. 2005a)
What Are Gas Hydrates?
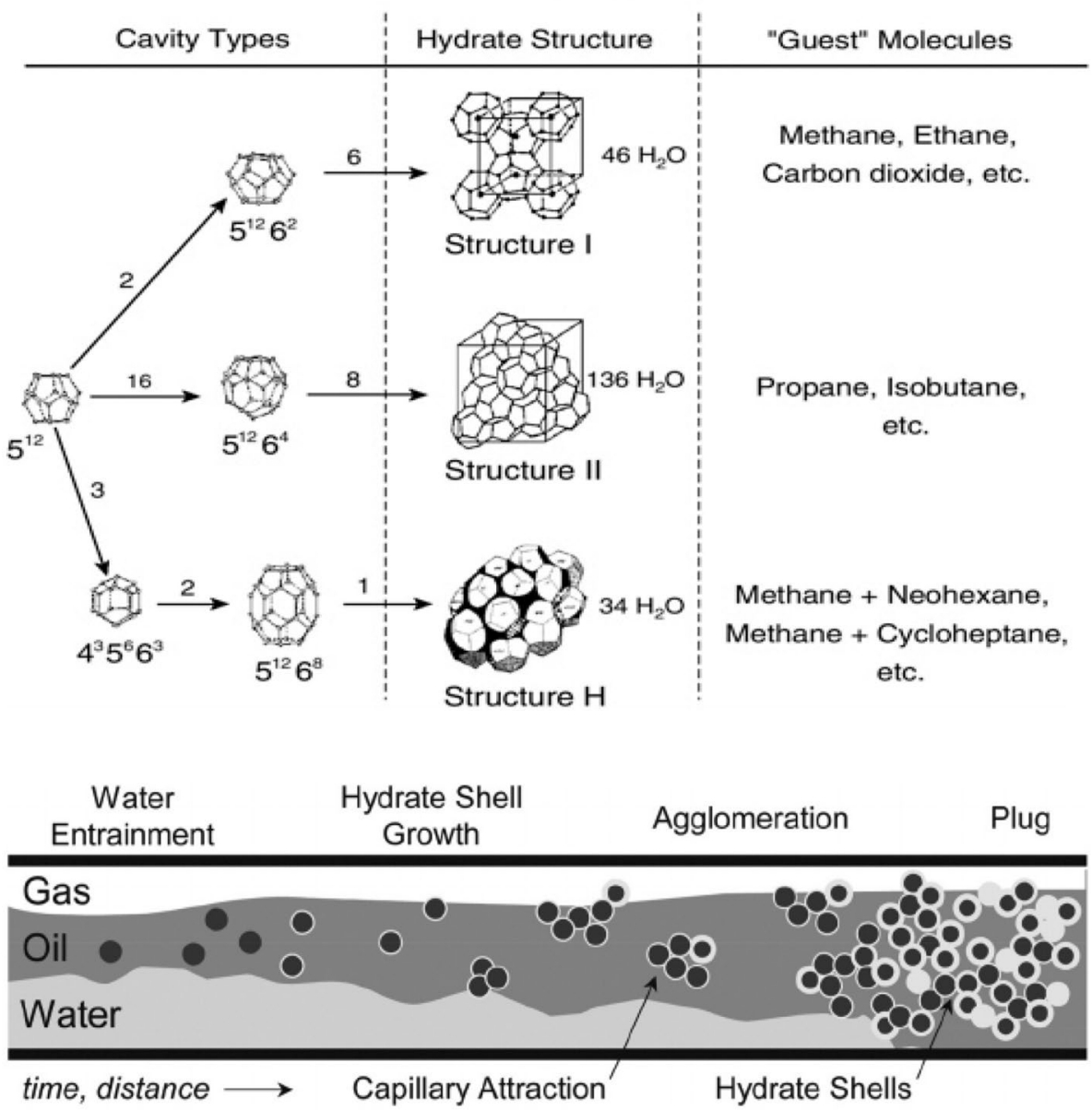
hydrate shells as a result of capillary attraction, leading to the formation of hydrate plugs.

\section{Effects of hydrates formation on production}

Hydrates could pose severe problems to the optimization of production from oil and gas production facilities, especially offshore. Hydrates can occur in gas and gas/condensate wells as well as in oil wells. Location and intensity of hydrate accumulation in a well vary and depend on the following key factors:

\section{- Operating regime}

- Design

- Geothermal gradient in the well

- Fluid composition

Key effects that hydrates plugs can cause include the blocking of production pipeline-riser systems, blocking of subsea transfer lines, forming in the wellbore, blow-out preventer and choke lines; in the event of gas-kick, thereby affecting drilling operations. It is also important to note that the partial or complete plug of the inner part of a gas pipeline, if not quickly removed, develops into high-pressure build-up inside the pipeline and leads to subsequent collapse of the pipeline (Obanijesu et al. 2010).

In terms of cost implication, problems encountered as a result of gas hydrates have typically cost the petroleum industry billions of US dollars annually and have led to huge loss of production time, as a result of shut-in of production wells. On an average, gas or gas-condensate field annual expenses for hydrate prevention are in the range of 5-15 million US dollars. Citing (Makogon et al. 1996), also expenses for the removal of a complete hydrate plug in a well or gas or oil pipeline offshore are usually several millions of US dollars (Makogon et al. 1996).

\section{Hydrate mitigation strategies}

Hydrate mitigation strategies are an important aspect of designing offshore production systems as it prevents formation of hydrates in pipeline, which can lead to deferred production and in some cases loss of equipment.

\section{Monoethylene glycol (MEG)}

MEG is an example of thermodynamic hydrate inhibitor (THI). MEG inhibitors are by far the most commonly used method for hydrates control, as a result of their widespread availability. They compete with water molecules in terms of hydrogen bonding, making the formation of hydrates thermodynamically less likely. This implies that THIs are the robust choice for long-distance gas-condensate tie-backs.
The most used thermodynamic inhibitors are methanol $(\mathrm{MeOH})$ and monoethylene glycol (MEG). Alcohols and glycols may be used; however, the main factor making methanol and MEG the most common thermodynamic inhibitors is hydrate suppression performance (Brustad et al. 2005). Methanol and MEG are currently the most common avoidance method used for hydrate mitigation, mainly due to their effectiveness and highly developed thermodynamic models that enable reliable estimation of the THI volumes required for inhibition (Salmin et al. 2017); (Tohidi et al. 2015).

A drawback of THIs is that they require large volumes, for effective mitigation of hydrates; especially for oil and gas wells with high water-cut. Also, as the sub-cooling (the difference between the temperature at which hydrates are stable and the temperature at which the system operates) increases, more volume is required for efficient mitigation (Thieu and Frostman 2005). Also, with longer tie-backs, oil fields maturing and oil exploration moving into deeper waters, the effective dosage of THI becomes impractical (Cooley et al. 2003). The effective THI volume fraction required for hydrate inhibition can often go up to $50 \mathrm{vol} \%$ of the brine phase (Kelland et al. 2006).

\section{Low-dosage hydrate inhibitors}

Low-dosage hydrate inhibitors (LDHIs), such as KHIs and AAs, are an alternative method to mitigate the risk of forming a hydrate blockage, and these LDHIs can be effective at significantly lower-dosage levels than THIs (Frostman et al. 2003); (Braniff 2013). The application of LDHIs could allow safe deepwater petroleum production with a significant reduction in capital expenditure (CAPEX) and operational cost, as well as reducing production deferment, which extends the field lifetime (Salmin et al. 2017).

Low-dosage hydrate inhibitors are divided into:

- Kinetic hydrate inhibitors

- Anti-agglomerants

Kinetic hydrate inhibitors (KHIs) KHIs typically consist of water-soluble polymers which interfere with and delay hydrate crystal nucleation and initial crystal growth processes. The initial pointers to the chemical structures suitable for use as KHIs came from the observation that certain fish had the ability not to freeze in sub-zero seawater temperatures. The fish had the ability to produce a protein that (like a KHI with hydrate crystal) interacted with an ice crystal and inhibited the further growth of the ice crystal (Clark et al. 2005b).

The 'first-generation KHIs' were based on polymers of pyrrolidinone or caprolactam ring-based structures. The KHI limitation included sub-cooling limits and also time 
limits of the KHI effectiveness. The effectiveness of firstgeneration KHIs at controlling hydrates (at up to $14.4^{\circ} \mathrm{F}$ sub-cooling) was limited to approximately 24-h. The firstgeneration KHIs had upper limits on the sub-cooling, and they could effectively control up to $18{ }^{\circ} \mathrm{F}$ ) as noted by (Ke and Kelland 2016).

The new technologies in KHIs have extended the effectiveness of the first-generation KHIs to up to $23.4^{\circ} \mathrm{F}$ (for days to weeks depending on the sub-cooled). The major disadvantage is that it cannot be used for higher sub-cooling temperature like that of ultra-deep subsea system.

Anti-agglomerants These are surfactants that attack the hydrates and disperse it to smaller particles. Anti-agglomerants operate via a different mechanism to KHIs. AAs allow hydrate crystals to form, but in doing so, the hydrate crystals are kept small and non-adherent.

AAs are thought to have the ability to change the crystal size of hydrates and the morphology of their agglomerates by incorporating the inhibitor molecule into the hydrate crystal lattice (Fu et al. 2002).

It has the following limitations:

- Require liquid hydrocarbon phase

- Do not protect gas phase
- May not be effective at temperature below $38^{\circ} \mathrm{F}$ (Frostman et al. 2003)

\section{Simulation model}

In this study, numerical simulation approach and compositional analysis were deployed in studying the technical effectiveness and cost-effectiveness of MEG and LDHI hydrates inhibition strategies. There are several multiphase flow simulators such as PIPESIM, MAXIMUS and OLGA that could be used for this study. However, MAXIMUS was used as its integrated production modelling (IPM) capacity entails that it can model key reservoir and well attributes, subsea conditions and topsides conditions as well, thereby enabling a better prediction of the hydrates behaviour being studied.

Mathematically, oil and gas production systems comprised of wells, flowlines, risers and topsides processing facilities form diagraphs of nodes, connected together by branches. Figure 3 shows a three-well subsea production system, comprised of separators and re-compression systems on the topsides. For the purpose of analysis, all equipment that has a single fluid input and output is defined as branches, leaving nodes. In solving the corresponding network problem, MAXIMUS deploys equation-oriented

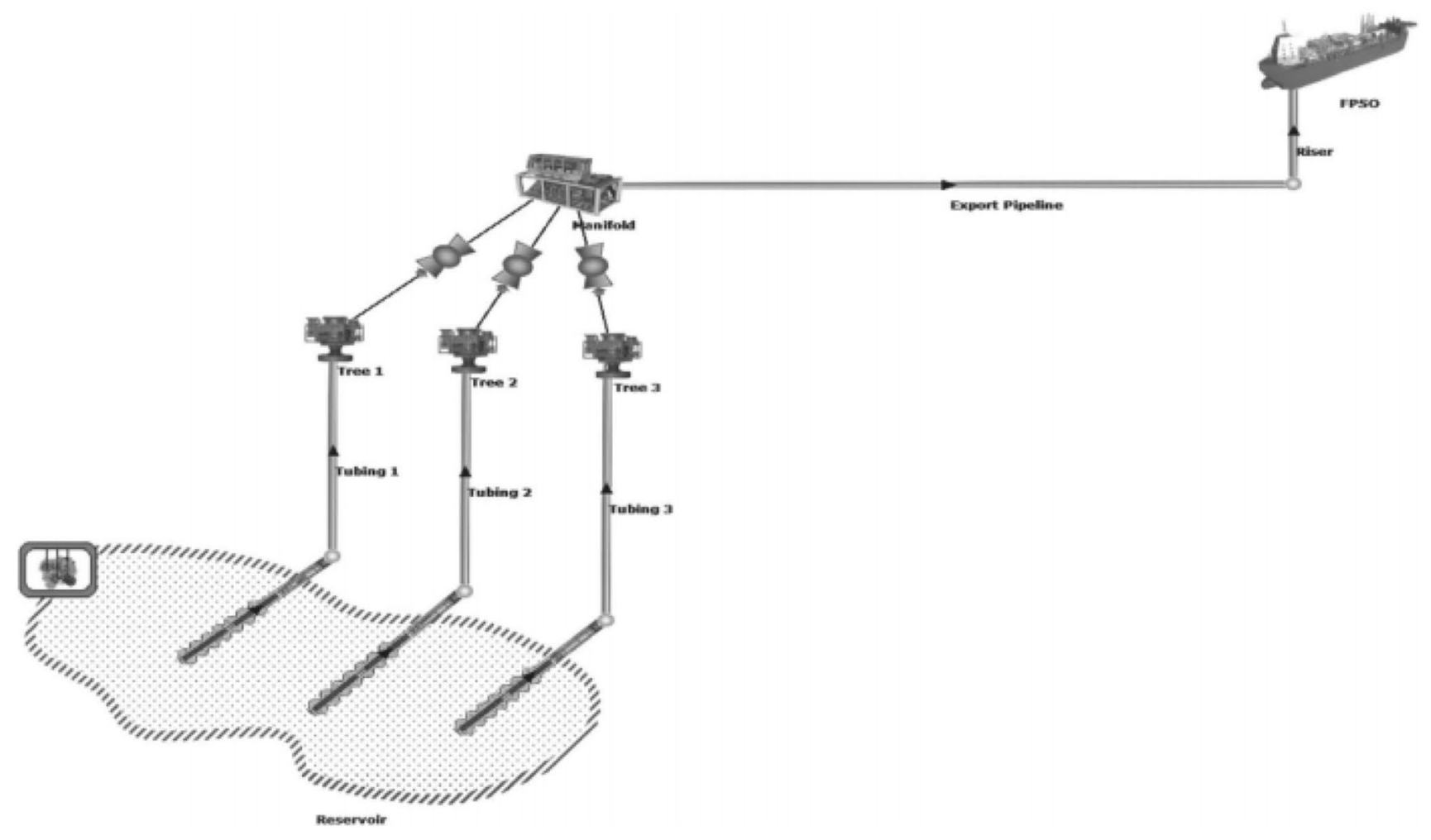

Fig. 3 Example model: three-well oil production system (Watson et al. 2007) 
solution to the problem. The advantage of equation-based approach is its ability to reduce a problem to the most convenient set of sub-problems before solution. In general, the system of equations formulated is nonlinear and takes the form:

$F(x)=0$

where

$F=\left(F_{1}, F_{2} \ldots, F_{i}, \ldots F_{N-1}, F_{N}\right)^{\mathrm{T}}$

and

$x=\left(x_{1}, x_{2} \ldots, x_{i}, \ldots x_{M-1}, x_{M}\right)^{\mathrm{T}}$.

In solving the system of equations, $M-N$ specifications are made. In order to achieve the specification of $M-N$, boundary conditions for the network, for example, source and sink pressures and flow rates, must be defined. Modelling parameters such as tubing diameter, flowline diameter and pump duties must be defined, for the solution to the problem to be derived from the simulation. (Watson et al. 2007).

\section{Fluid characterization}

MAXIMUS offers two fluid model options for modelling physical properties and phase behaviour (black oil and compositional). Black oil is characterized in terms of a small number of key parameters such as stock tank oil density and the stock tank GOR, and empirical correlations are used to predict the phase behaviour and fluid physical properties. Compositional fluid characterization is based on the amount of particular components comprising the fluid and the use of an equation of state (EoS) to predict the phase behaviour and thermodynamic functions. The compositional approach has a sound scientific basis and was adapted for this study.

In this study, compositional analysis was used to characterize the fluid. The characterization was based on compositional analysis of the fluid. MAXIMUS performs a recombination and characterization with two separate fluid PVT analyses corresponding to separator gas and liquid. The target GOR is then entered, including oil molecular weight and specific gravity.

\section{Field case-study}

As key part of this work, a sample deepwater oil field, operating at about $1,000 \mathrm{~m}$ water depth, was considered for this study. The reservoir pressure was 2650 psia, based on the field data obtained from operators. The API of the oil is $35.4^{\circ} \mathrm{API}$. At single-stage flash, the fluid GOR is deduced
Table 1 Fluid composition of the field

\begin{tabular}{|c|c|c|}
\hline Components & Gas mole $(\mathrm{g} / \mathrm{mol})$ & Oil mass $(\mathrm{kg})$ \\
\hline Methane & 68.87 & 0 \\
\hline Nitrogen & 0.254 & 0 \\
\hline Ethane & 7.917 & 0.01 \\
\hline $\mathrm{H}_{2} \mathrm{~S}$ & 0 & 0 \\
\hline $\mathrm{CO}_{2}$ & 1.421 & 0 \\
\hline Propane & 8.675 & 0.091 \\
\hline iC4 $i$-butane & 1.282 & 0.047 \\
\hline nC4 $n$-butane & 4.197 & 0.247 \\
\hline iC5 $i$-pentane & 1.407 & 0.254 \\
\hline nC5 $n$-pentane & 1.55 & 0.384 \\
\hline C6 & 1.485 & 1.093 \\
\hline $\mathrm{C} 7$ & 0.845 & 2.432 \\
\hline $\mathrm{C} 8$ & 0.398 & 3.586 \\
\hline $\mathrm{C} 9$ & 0.181 & 3.209 \\
\hline $\mathrm{C} 10$ & 0.065 & 3.897 \\
\hline $\mathrm{C} 11$ & 0.016 & 3.682 \\
\hline $\mathrm{C} 12$ & 0.003 & 3.481 \\
\hline $\mathrm{C} 13$ & 0 & 3.898 \\
\hline $\mathrm{C} 14$ & 0 & 3.289 \\
\hline $\mathrm{C} 15$ & 0 & 3.409 \\
\hline $\mathrm{C} 16$ & 0 & 2.895 \\
\hline $\mathrm{C} 17$ & 0 & 2.762 \\
\hline $\mathrm{C} 18$ & 0 & 3.011 \\
\hline C19 & 0 & 2.916 \\
\hline $\mathrm{C} 20$ & 0 & 2.261 \\
\hline $\mathrm{C} 21$ & 0 & 2.179 \\
\hline $\mathrm{C} 22$ & 0 & 2.124 \\
\hline $\mathrm{C} 23$ & 0 & 2.002 \\
\hline $\mathrm{C} 24$ & 0 & 1.898 \\
\hline $\mathrm{C} 25$ & 0 & 1.866 \\
\hline $\mathrm{C} 26$ & 0 & 1.674 \\
\hline $\mathrm{C} 27$ & 0 & 1.611 \\
\hline $\mathrm{C} 28$ & 0 & 1.645 \\
\hline $\mathrm{C} 29$ & 0 & 1.6 \\
\hline $\mathrm{C} 30+$ & 0 & 1.737 \\
\hline
\end{tabular}

as $1324 \mathrm{scf} / \mathrm{stb}$. The fluid composition, based on PVT study, is as highlighted in Table 1, with key components such as methane captured as $68.87 \mathrm{~g} / \mathrm{mol}$, ethane as $7.917 \mathrm{~g} / \mathrm{mol}$ and carbon dioxide $\left(\mathrm{CO}_{2}\right)$ captured as $1.421 \mathrm{~g} / \mathrm{mol}$. In modelling the fluid in MAXIMUS, the accuracy of the fluid composition was determined after carrying out flash calculations at standard conditions $\left(60^{\circ} \mathrm{F}\right.$ and $\left.14.7 \mathrm{psia}\right)$. The predicted GOR was obtained at within $\pm 2 \%$ of the target GOR (1324 scf/stb); hence, the modelling proceeded. Average produced water rate of $6055 \mathrm{STB} / \mathrm{d}$ was modelled; to capture the field scenario.

In defining the LDHI, the composition was modelled as follows: loading of $19.8 \mathrm{~g}(0.2 \mathrm{~mol})$ 


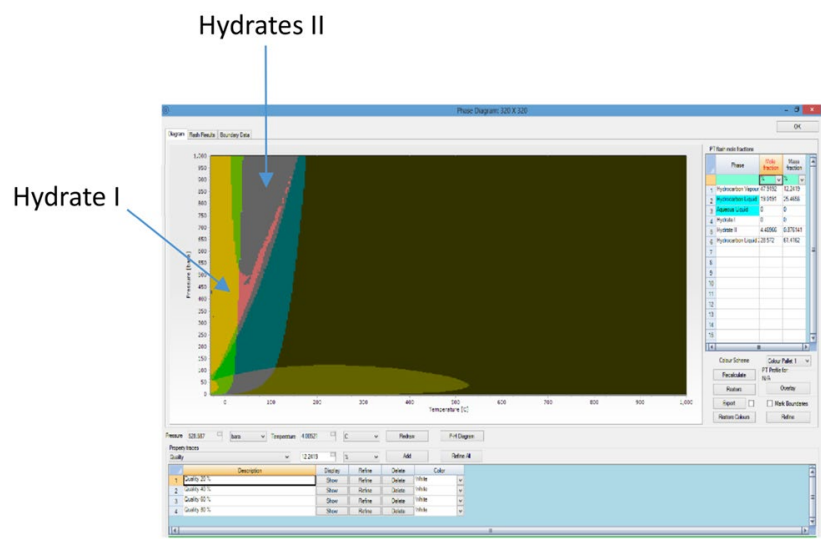

Fig. 4 Phase diagram

$N$-methyl- $N$-vinylacetamide and $27.8 \mathrm{~g}(0.2 \mathrm{~mol})$ added to form vinylcaprolactam.

The phase behaviour of the reservoir fluid over a pressure range of $(0-1200$ bara $)$ and a temperature range of $\left(-20^{\circ} \mathrm{C}\right.$ to $1000{ }^{\circ} \mathrm{C}$ ) was deduced, and the phase diagram is presented in Fig. 4. Hydrates I phase formed at temperature and pressure ranges of about $\left(-20-10^{\circ} \mathrm{C}\right)$ and a pressure range of (0-10,000 bara). Hydrate phase $\mathrm{I}$ is also captured in the light brown section as shown in Fig. 4, while hydrates II phase formed at temperature range of about $\left(0-110^{\circ} \mathrm{C}\right)$ and a pressure range of $(0-10,000$ bara). The hydrates II phase is shown in ash-coloured region in Fig. 4.

\section{Equation of state}

To begin characterization, an equation of state (Pedersen) is added to the simulation model being built in order to correlate it with the laboratory data. Equations of state can be used over wide ranges of temperature and pressure, including the sub-critical and supercritical regions. They are frequently used for ideal or slightly non-ideal systems such as those related to the oil and gas industry when modelling hydrocarbon systems.

The viscosity prediction against pressure with results from the default liquid correlation (Pedersen with fitting) is seen in Fig. 5, indicating a reasonable fit to the field data, with a slight variation; as captured in the blue marker point and the brown points.

\section{Production model}

A production system was built mirroring that of a real field. The production model comprises a table model, completion, tubing, wellhead, pipeline and a source for injection of inhibitor into the system.

Table 2 Tubing geometry

\begin{tabular}{lcc}
\hline Measured depth (m) & True vertical depth (m) & $\begin{array}{l}\text { Ambient } \\
\text { temperature } \\
\left({ }^{\circ} \mathrm{C}\right)\end{array}$ \\
\hline 579 & 579 & 4 \\
669 & 571 & 8 \\
1258 & 952 & 10 \\
1470 & 1085 & 12 \\
1821 & 1302 & 18 \\
1907 & 1363 & 25 \\
\hline
\end{tabular}

Fig. 5 Graph showing data from PVT matched with predicted data from Pedersen viscosity correlation

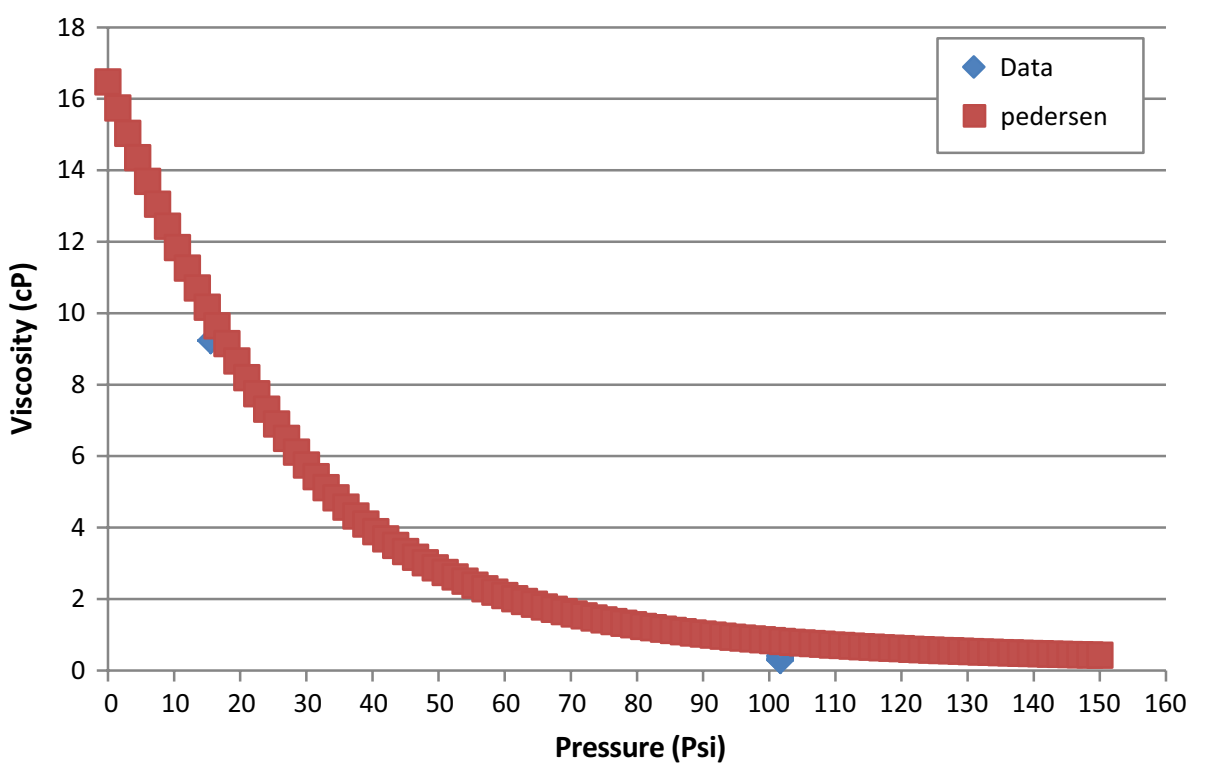




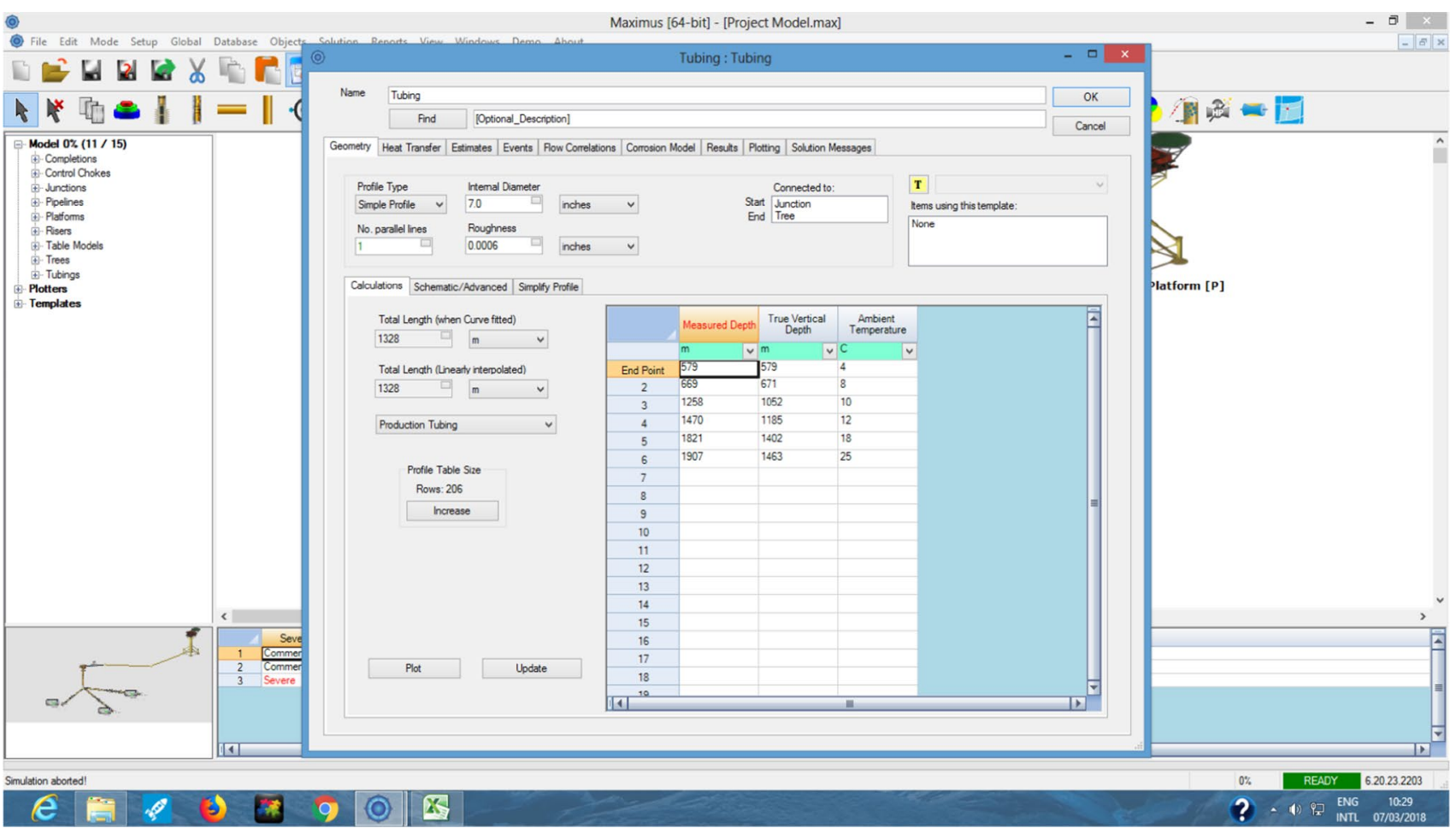

Fig. 6 Tubing interface MAXIMUS

Table 3 Pipeline geometry

\begin{tabular}{lll}
\hline Horizontal distance $(\mathrm{m})$ & Elevation $(\mathrm{m})$ & $\begin{array}{l}\text { Ambient } \\
\text { temperature } \\
\left({ }^{\circ} \mathrm{C}\right)\end{array}$ \\
\hline 0 & -989 & 4 \\
1300 & -985 & 4 \\
4100 & -995 & 4 \\
4900 & -1000 & 4 \\
6400 & -985 & 4 \\
6800 & -980 & 4 \\
7200 & -975 & 4 \\
7900 & -970 & 4 \\
8700 & -965 & 4 \\
9600 & -960 & 4 \\
10,200 & -955 & 4 \\
11,200 & -950 & 4 \\
12,900 & -945 & 4 \\
\hline
\end{tabular}

\section{Tubing}

The tubing is used to move produced fluid to the surface. Tubing strings must be sized properly to enable fluid flow efficiently. The measured depth, true vertical depth and corresponding ambient temperature for the field case-study are

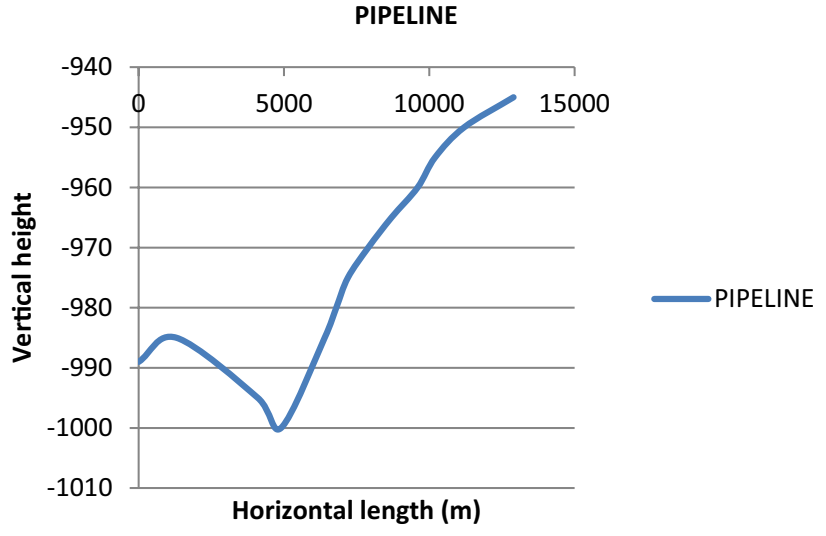

Fig. 7 Pipeline geometry

given in Table 2. The tubing interface on MAXIMUS is also shown in Fig. 6. 
Table 4 Riser geometry

\begin{tabular}{lrl}
\hline Horizontal distance $(\mathrm{m})$ & Elevation $(\mathrm{m})$ & $\begin{array}{l}\text { Ambient } \\
\text { temperature } \\
\left({ }^{\circ} \mathrm{C}\right)\end{array}$ \\
\hline 0 & -945 & 4 \\
70 & -600 & 4 \\
102 & -100 & 4 \\
105 & 0 & 10 \\
106 & 40 & 20 \\
\hline
\end{tabular}

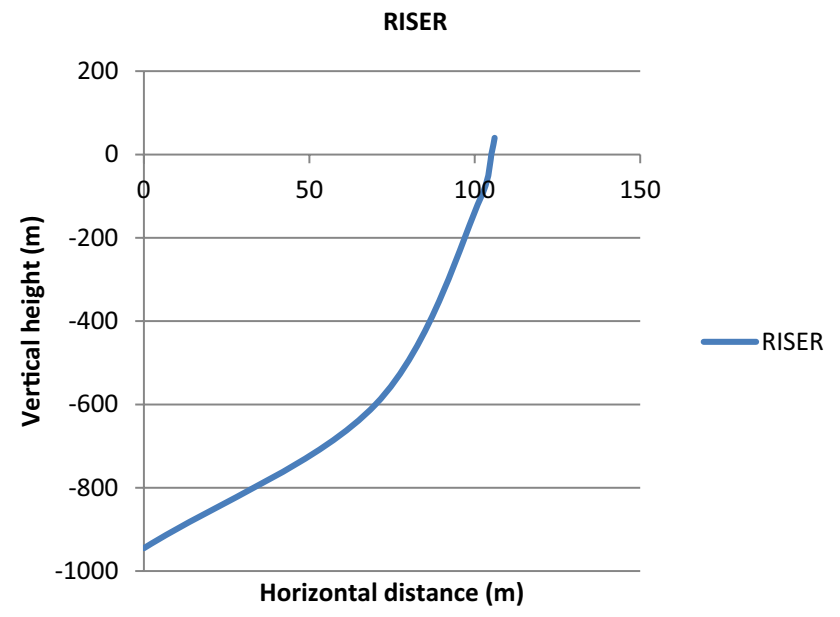

Fig. 8 Riser geometry

\section{Pipeline}

The pipeline horizontal distance, elevation and ambient temperature for the field case-study are given in Table 3, and a sketch of the pipeline geometry is shown in Fig. 7.

\section{Riser}

It is the conduit to transfer fluid from the seafloor to production facilities atop the water surface. Table 4 shows the riser geometry for the case-study considered in this work, and Fig. 8 shows the riser geometry.

\section{Source}

The source highlighted in the green box in Fig. 9 is modelled as the point of injection of the hydrate inhibitor within the pipeline-riser system. At the source, the injection rate for $\mathrm{MEG}$ was $250 \mathrm{gal} / \mathrm{day}$, while the injection rate adopted for LDHI was $40 \mathrm{gal} /$ day.

\section{Results and discussion}

This section of the paper focused on analysing the results generated from the simulation of various scenarios. The base case and subsequent cases involving MEG and LDHI hydrates mitigation were analysed.

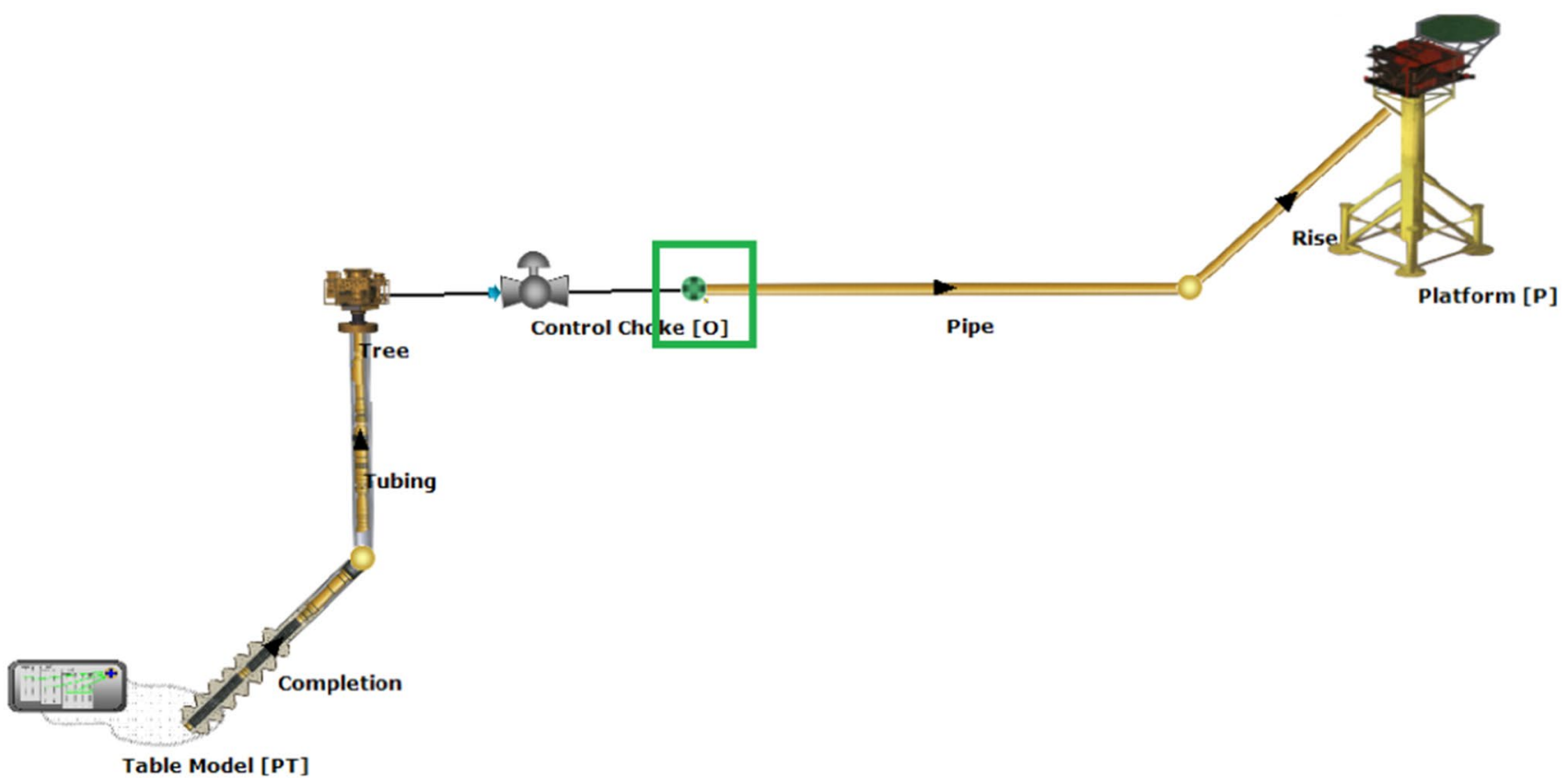

Fig. 9 Complete production model showing source used for injection 

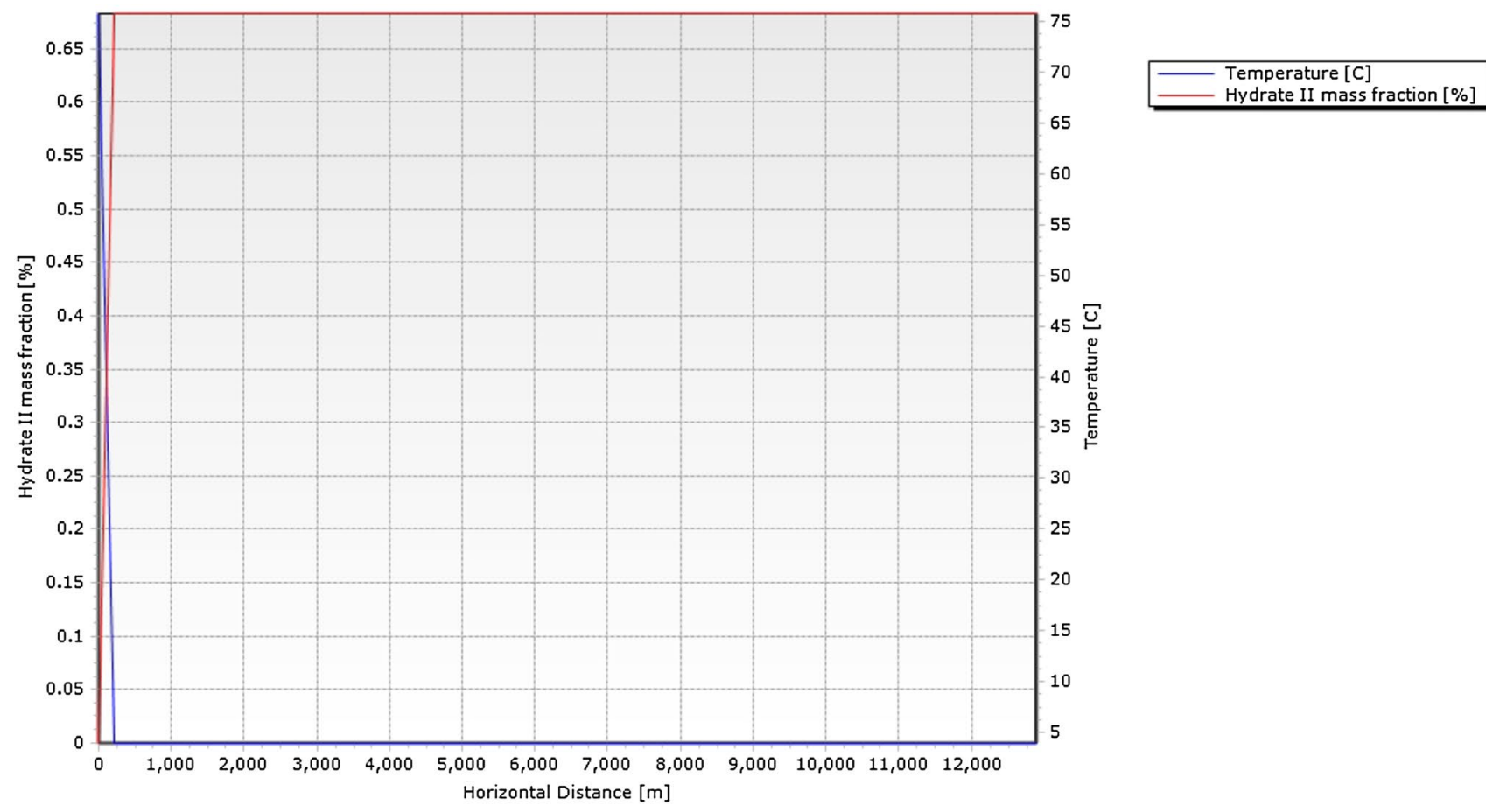

Fig. 10 Pipeline profile showing hydrate II mass fraction

\section{Without any injection of inhibitors (base case)}

The production system was simulated to be producing without injection of hydrate inhibitors for the first five (5) years. Figure 10 shows the temperature-hydrate mass fraction profile for the pipe with hydrate mass fraction in red becoming stable at over $0.65 \%$ hydrate mass fraction in red marker colour and at a temperature slightly below $5{ }^{\circ} \mathrm{C}$ highlighted in blue marker point around the $250 \mathrm{~m}$ horizontal pipe length. The sharp change in temperature between the 0 - and 250-m-pipe-length sections enhanced the formation of hydrate and this became stable, as the temperature behaviour also remained stable below $5{ }^{\circ} \mathrm{C}$.

\section{Case 1}

In this scenario, MEG was injected to prevent formation of hydrates in the pipeline-riser system. Monoethylene glycol is by far the most commonly used method for hydrate control (Fig. 11).

Initially, simulation was run at $150 \mathrm{gal}$ of MEG; however, the simulation crashed, as hydrates were not mitigated and rather pressure was built up within the pipeline-riser system, leading to the network not being solved.

As it can be seen from Fig. 12, the monoethylene glycol (MEG) completely inhibited the formation of hydrates along the pipeline after $250 \mathrm{gal}$ of MEG was injected at about
$4.2 \mathrm{gal} / \mathrm{h}$ for approximately $6 \mathrm{~h}$ of operation, as observed in the red hydrate mass fraction line at zero. A general trend of drop in temperature profile observed in the blue line from about $5{ }^{\circ} \mathrm{C}$ to about $4.1{ }^{\circ} \mathrm{C}$ was also observed, highlighting the ability of the kinetic hydrate inhibitor to mitigate hydrates by controlling temperature (Fig. 13).

\section{Case 2}

In the case 2 scenario, a sample KHI (poly [VIMA/VICAP]), whose compound structure is given in "Appendix", was injected as an example of low-dosage hydrate inhibitor into the production system. The behaviour of poly [VIMA/ VICAP] in mitigating the hydrates formation is observed in the irregular fluctuation in pressure in the blue staggered line and temperature in the red declining line shown in Fig. 14, indicating that the LDHI was preventing stable nucleation of hydrates mass fraction.

In Fig. 15, a plot of temperature against hydrate mass fraction confirms that the LDHI was able to mitigate the hydrate formation as observed in the red line indicating a $0 \%$ hydrate mass fraction after the LDHI was injected at about $6.7 \mathrm{gal} / \mathrm{h}$ rate for approximately $6 \mathrm{~h}$ of operation. This therefore indicates that irrespective of the irregular fluctuation in pressure and temperature behaviour, LDHI was able to mitigate the formation of hydrates as nucleation of hydrates molecules was prevented. In Fig. 13, simulation error messages were observed when an attempt was made to 


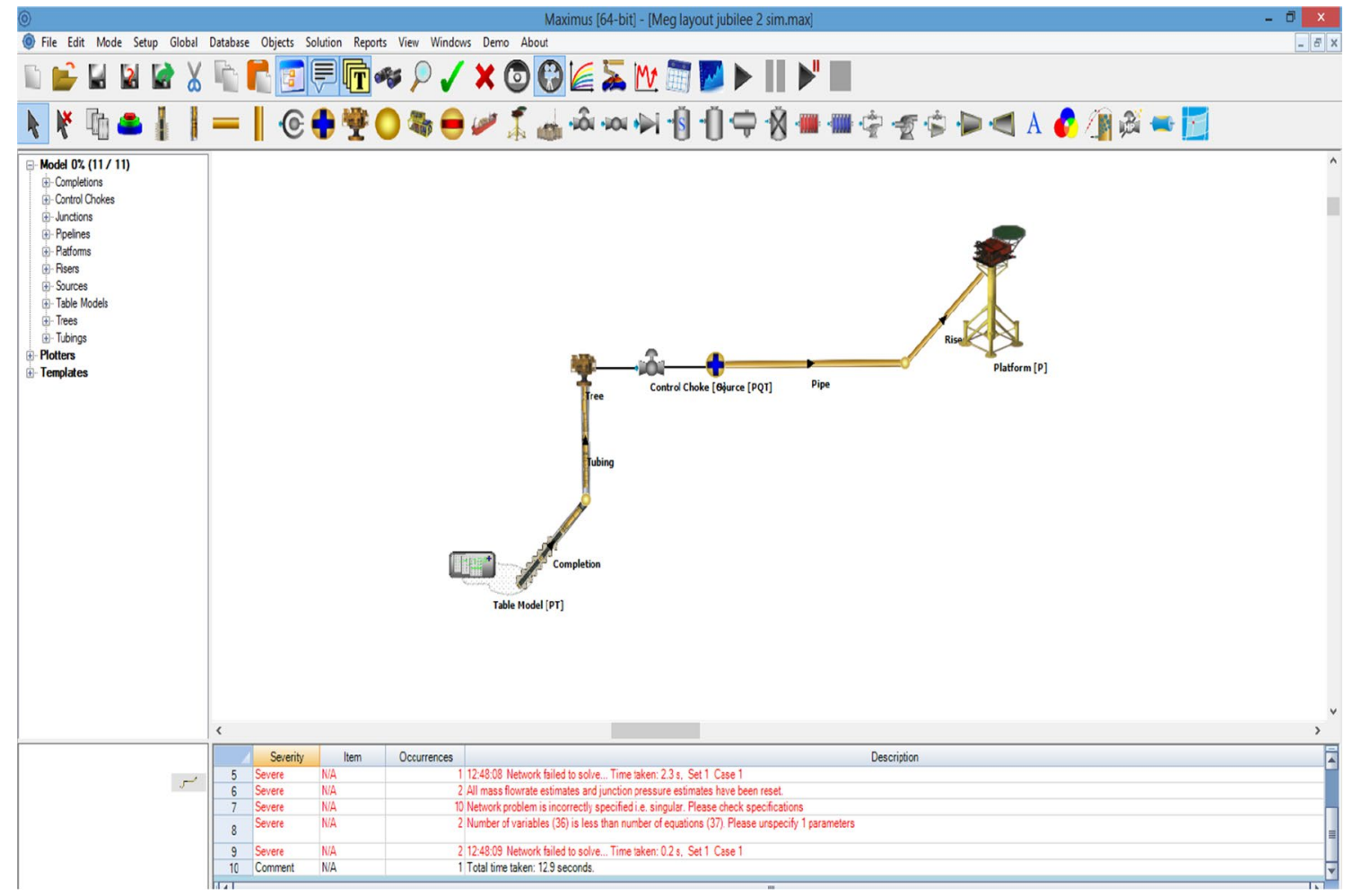

Fig. 11 Simulation showing that MEG crashed at $150 \mathrm{gal}$

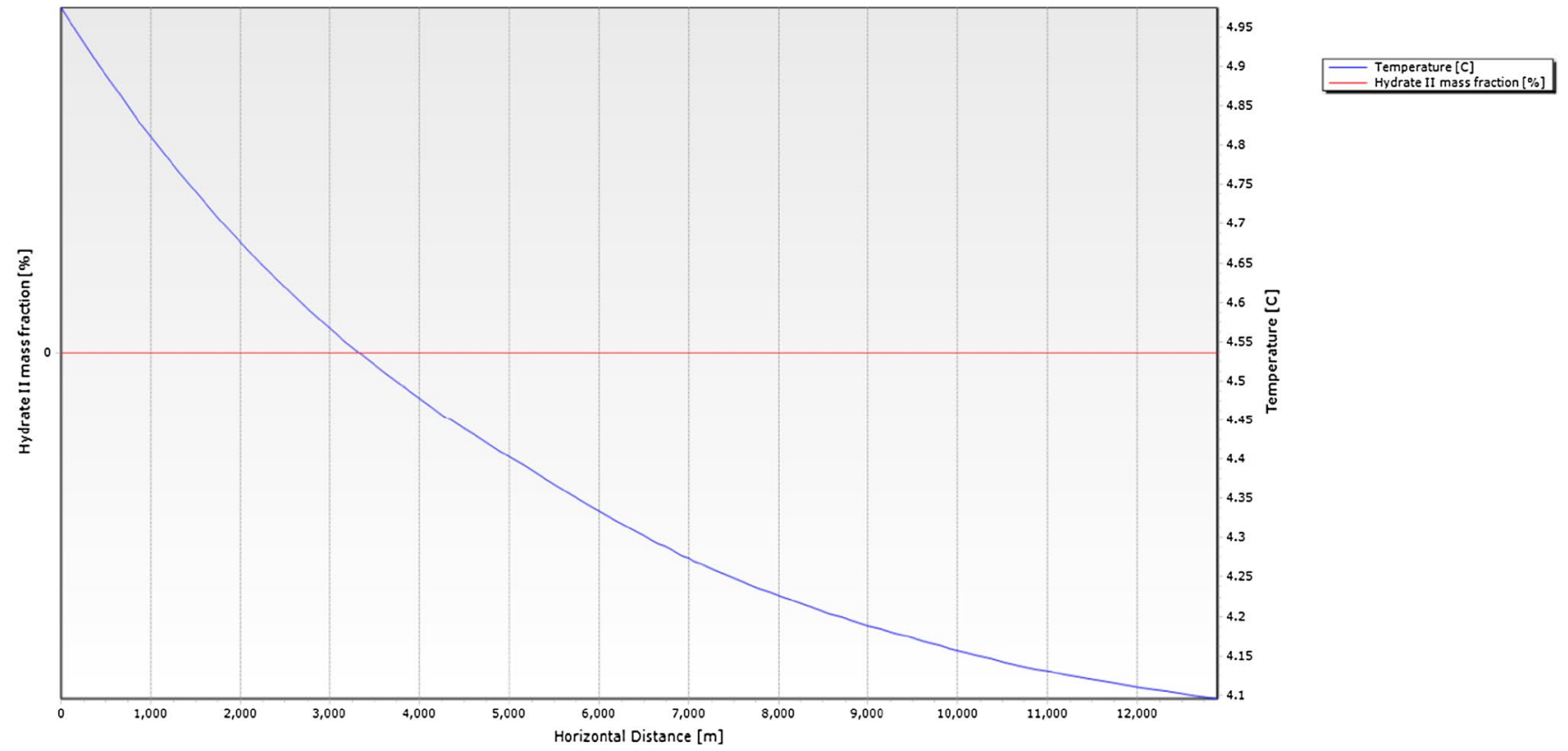

Fig. 12 Pipeline profile after MEG inhibition 


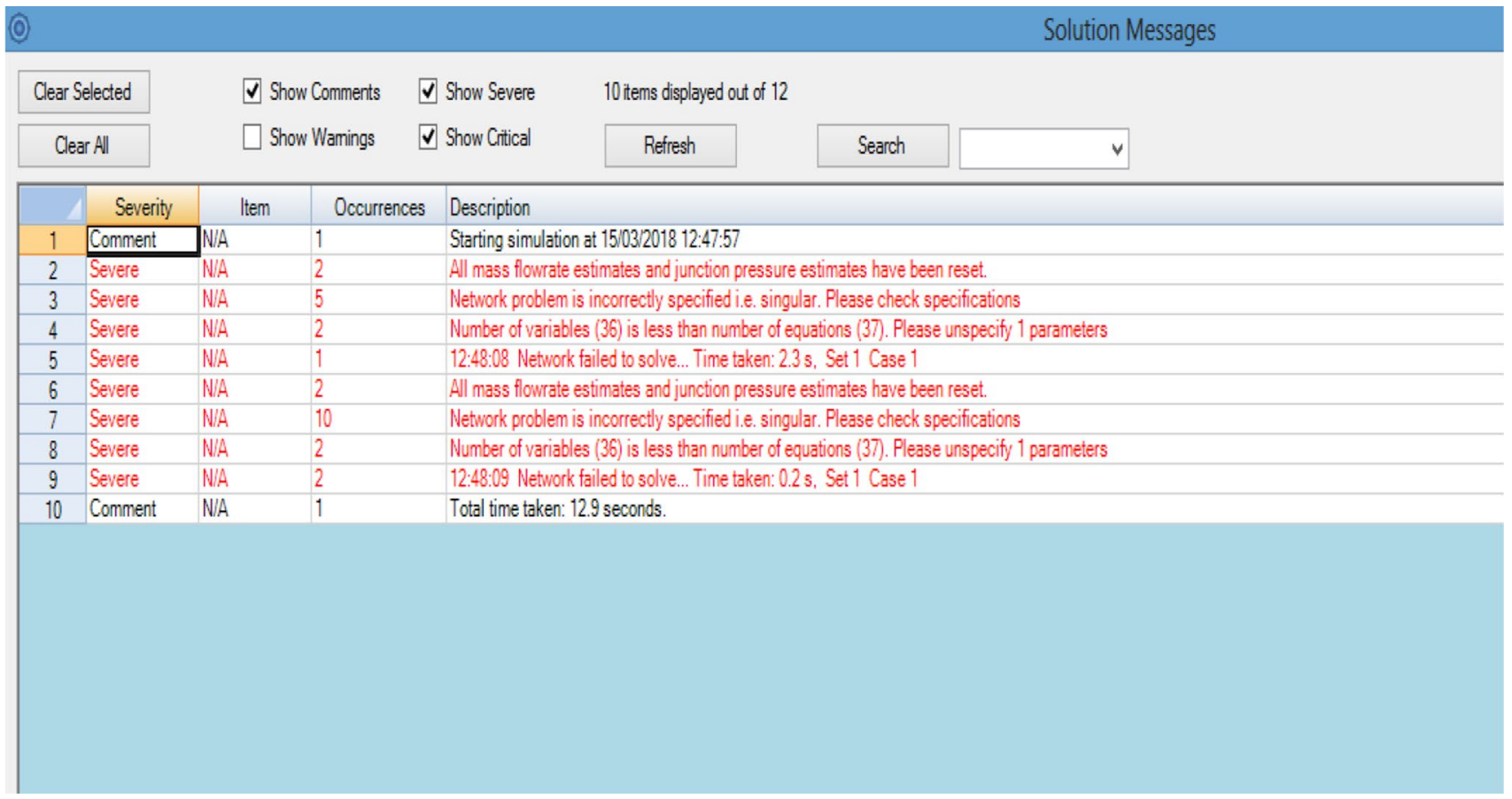

Fig. 13 Simulation run error messages for LDHI at $10 \mathrm{gal} / \mathrm{h}$

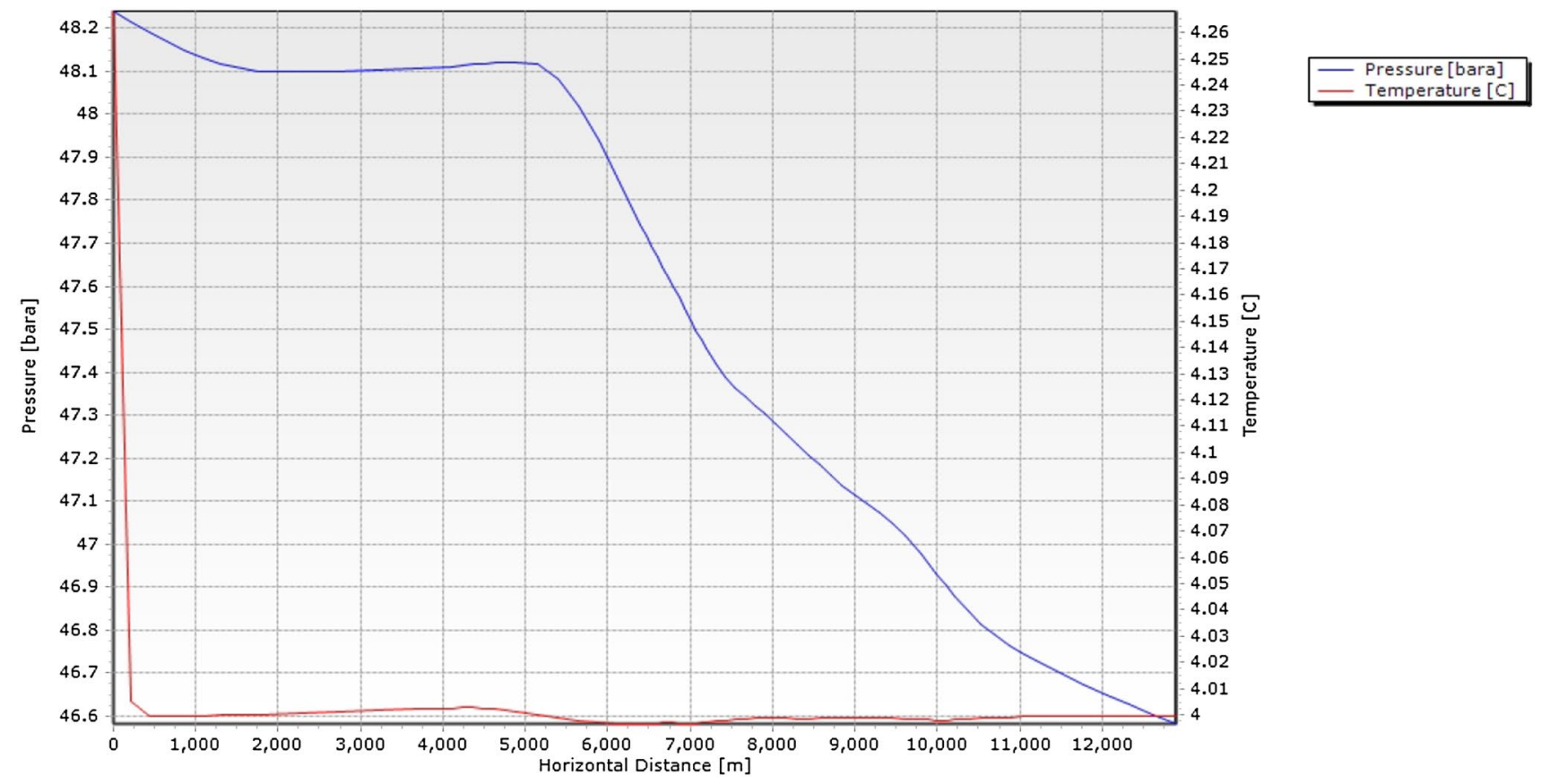

Fig. 14 Pipeline profile after LDHI injection

model a lower volume of LDHI (2 gal/h); for the mitigation of hydrates. The $2 \mathrm{gal} / \mathrm{h}$ was not sufficient in creating a scenario, where the inhibitor (LDHI) could have a reasonable volume/dosage that could prevent the nucleation of hydrates molecules. Hence, there was also pressure build-up, leading to the pipe network equations not being solvable. 

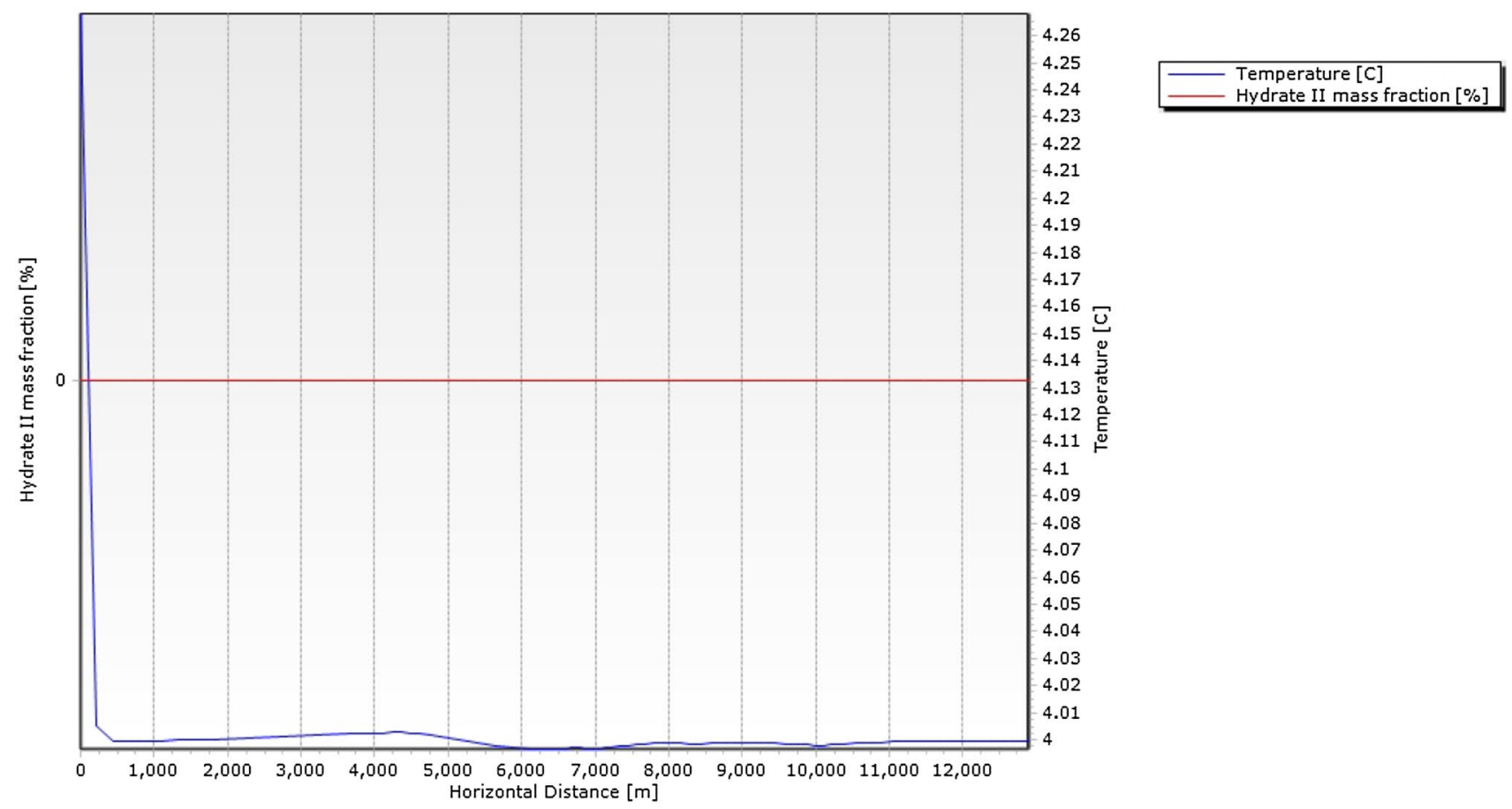

Fig. 15 Pipe profile showing hydrate mass fraction after injection of kinetic hydrate inhibitor

\section{Economic analysis}

In Table 5, an economic analysis was done based on typical rates/volumes of MEG and LDHI that are deployed for mitigating hydrates on sample offshore assets. Data on the volumes were obtained from an operator in deepwater West Africa, which was also modelled on the simulation tool, via the inhibitor injection point. Also, the data obtained as regards cost suggest that the cost of MEG per gal ranged from \$1.75-\$3.75/gal, while the cost of LDHI per gal was obtained as $\$ 10 /$ gal. Cost analysis was done based on the volume of MEG and LDHI simulated to inhibit the hydrates formation in the case-study. Two hundred and fifty gallons of MEG deployed and $40 \mathrm{gal}$ of LDHI were deployed in

Table 5 Economic analysis

\begin{tabular}{lll}
\hline & Monoethylene glycol & $\begin{array}{l}\text { Low-dosage } \\
\text { hydrate inhibitor } \\
(\mathrm{LDHI})\end{array}$ \\
\hline Cost & $\$ 1.75-\$ 3.75 / \mathrm{gal}$ & $\$ 10 / \mathrm{gal}$ \\
Injection rate & $250 \mathrm{gal} /$ day & $40 \mathrm{gal} / \mathrm{day}$ \\
Total cost & $250 \times 3.75=937.5 \$ /$ day & $40 \times 10=400 \$ /$ day \\
\hline
\end{tabular}

simulating the effect of MEG and LDHI in mitigating the hydrates formation in the case-study.

In the long run, the cumulative cost of using monoethylene glycol (MEG) was significantly higher than that of low-dosage hydrate inhibitor although low-dosage hydrate inhibitors had an initial relatively high CAPEX. In the long run, its OPEX is relatively low, making it cost-effective for hydrate inhibition in deepwater scenario.

The cost analysis was done based on typical cost rates obtained from an operator in offshore West Africa, as given in Table 5.

\section{Summary of results}

In summary, this study investigated the hydrates mitigation behaviour of a sample LDHI and MEG on a typical subsea environment which has high-pressure and low-temperature conditions favourable for hydrate formation in the pipelineriser system.

Analysis of the results obtained indicated that MEG inhibited the hydrate mass fraction formation by mainly controlling the temperature condition. Also, from the simulation results LDHI mitigated hydrates by causing an irregular fluctuation in pressure, which prevented the nucleation or growth of hydrate mass fraction to form hydrates. 
Although MEG showed a better hydrate suppression ability by exhibiting better control on temperature, LDHI, however, was more cost-effective from the economic analysis with a potential savings of over $\$ 500 /$ day when deployed.

\section{Conclusions}

This study highlighted the effect of low temperature and high pressure as key conditions for hydrates formation in deepwater scenario. A thorough review was also done on the mechanism of MEG and LDHI hydrates inhibition strategies.

Numerical simulation study based on a sample deepwater West African oil field was also done via MAXIMUS 6.20 an integrated production modelling (IPM) tool. The results of the simulation study showed that MEG did perform better in mitigating hydrates by controlling temperature. However, considering that LDHI also mitigated hydrates, after causing a fluctuation in pressure which subsequently prevented the effective nucleation of hydrates mass fraction to form hydrates and the relatively lower OPEX cost associated with deploying LDHI, it is recommended for hydrates mitigation in deepwater scenario.

Acknowledgements The authors seize this medium to acknowledge $\mathrm{KBC}$ for the release of MAXIMUS software academic license which was deployed for the simulation study. Also, the authors are particularly grateful to Olumayowa Finiyi for her support during the simulation stage of the work.

Open Access This article is distributed under the terms of the Creative Commons Attribution 4.0 International License (http://creativeco mmons.org/licenses/by/4.0/), which permits unrestricted use, distribution, and reproduction in any medium, provided you give appropriate credit to the original author(s) and the source, provide a link to the Creative Commons license, and indicate if changes were made.

\section{Appendix}

See Fig. 16.

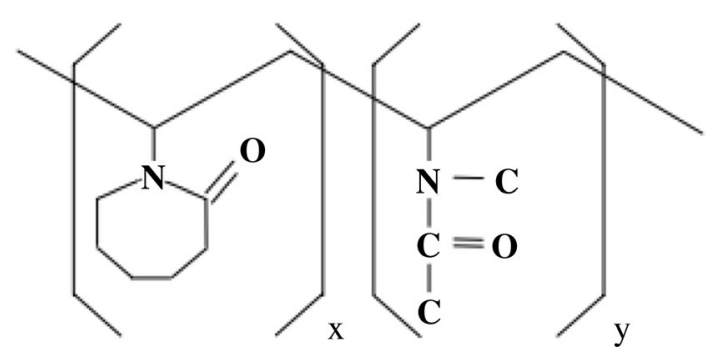

Fig. 16 The poly [VIMA/VCAP]

\section{References}

Braniff MJ (2013) Effect of dually combined under-inhibition and antiagglomerant treatment on hydrate slurries. Colorado School of Mines, Arthur Lakes Library, Golden

Brustad S, Løken K-P, Waalmann JG et al (2005) Hydrate prevention using MEG instead of $\mathrm{MeOH}$ : impact of experience from major Norwegian developments on technology selection for injection and recovery of MEG. In: Offshore technology conference

Clark LW, Frostman LM, Anderson J (2005a) Advances in flow assurance technology for offshore gas production systems. In: Nternational petroleum technology conference. International petroleum technology conference

Clark LW, Frostman LM, Anderson J, Petrolite B (2005b) Low-dosage hydrate inhibitors (LDHI): advances in flow assurance technology for offshore gas production systems. In: International petroleum technology conference

Cooley C, Wallace BK, Gudimetla R et al (2003) Hydrate prevention and methanol distribution on Canyon express. In: SPE annual technical conference and exhibition

Frostman LM, Thieu V, Crosby DL, Downs HH et al (2003) Lowdosage hydrate inhibitors (LDHIs): reducing costs in existing systems and designing for the future. In: International symposium on oilfield chemistry

Fu SB, Cenegy LM, Neff CS et al (2001) A summary of successful field applications of a kinetic hydrate inhibitor. In: SPE international symposium on oilfield chemistry

Fu B, Neff S, Mathur A, Bakeev K (2002) Application of low-dosage hydrate inhibitors in deepwater operations SPE 78823. SPE Prod Facil 17:133-137. https://doi.org/10.2118/78823-PA

Io A, Kara F, Nu O (2017) Investigation of slug mitigation : self-lifting approach in a deepwater oil field. Underw Technol 34:157-169. https://doi.org/10.3723/ut.34.157

Ke W, Kelland MA (2016) Kinetic hydrate inhibitor studies for gas hydrate systems: a review of experimental equipment and test methods. Energy Fuels 30:10015-10028

Kelland MA, Svartaas TM, Øvsthus J, Tomita T, Mizuta K (2006) Studies on some alkylamide surfactant gas hydrate anti-agglomerants. Chem Eng Sci 61:4290-4298

Makogon YF et al (1996) Formation of hydrates in shut-down pipelines in offshore conditions. In: Offshore technology conference

Minami K, Kurban APA, Khalil CN, Kuchpil C et al (1999) Ensuring flow and production in deepwater environments. In: Offshore technology conference

Obanijesu EO, Pareek V, Tade MO et al (2010) Hydrate formation and its influence on natural gas pipeline internal corrosion rate. In: SPE oil and gas India conference and exhibition

Okereke NU, Omotara OO (2018) Combining self-lift and gas-lift: a new approach to slug mitigation in deepwater pipeline-riser systems. J Pet Sci Eng 168:59-71. https://doi.org/10.1016/j.petro 1.2018.04.064

Processors, N.G. and Suppliers Association (1967) Engineering Data Book, 1st Edition

Salmin DC, Majid AAA, Wells J, Sloan ED, Estanga D, Kusinski G, Rivero M, Gomes J, Wu DT, Zerpa LE et al (2017) Study of anti-agglomerant low dosage hydrate inhibitor performance. In: Offshore technology conference

Thieu V, Frostman LM (2005) Use of low-dosage hydrate inhibitors in sour systems. In: SPE international symposium on oilfield chemistry. https://doi.org/10.2118/93450-MS

Tohidi B, Anderson R, Mozaffar H, Tohidi F (2015) The return of kinetic hydrate inhibitors. Energy Fuels 29:8254-8260

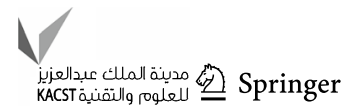


Wang Z, Zhao Y, Zhang J, Pan S, Yu J, Sun B (2018) Flow assurance during deepwater gas well testing: hydrate blockage prediction and prevention. J Pet Sci Eng 163:211-216

Watson MJ, Hawkes N, Pickering PF, Elliott JC, Studd LW et al (2007) Integrated flow-assurance modeling of the BP Angola block 18 western area development. SPE Proj Facil Constr $2: 1-12$

Publisher's Note Springer Nature remains neutral with regard to jurisdictional claims in published maps and institutional affiliations. 